\title{
ENTRE METAFICÇ̃̃O E METAFÍSICA, OU COMO NÃO INTERPRETAR PALE FIRE
}

\section{BETWEEN METAFICTION AND METAPHYSICS, OR HOW NOT TO READ PALE FIRE}

\section{Tauan Fernandes Tinti ${ }^{1}$}

RESUMO: O presente trabalho se propõe a explorar o problema da autoconsciência metaficcional na obra de Vladimir Nabokov a partir da figura de John Shade, o autor fictício de "Pale Fire", poema que integra o peculiar romance de mesmo título. A reflexão metafísica de Shade, ao ser separada do romance que a contém - uma possibilidade concretizada por uma edição de 2011 do poema, produzida pela Gingko Press -, serve então como via de acesso para se considerar a relação entre os diversos artistas criados por Nabokov e o próprio escritor. Isso levará, por sua vez, à investigação da concepção de natureza subjacente à sua obra, calcada na ideia de um criador bondoso que parece servir de modelo tanto para alguns de seus personagens quanto para a própria arte de Nabokov.

PALAVRAS-CHAVE: Vladimir Nabokov. Pale Fire. Metaficção. Modernismo tardio. Mimetismo natural.

ABSTRACT: This essay aims to investigate the problem of metafictional self-consciousness in the works of Vladimir Nabokov through the character John Shade, the fictitious author of "Pale Fire", a poem which is part of a peculiar novel bearing the same title. Shade's metaphysical meditation, when separated from the novel that contains it - a possibility realized by Gingko Press, which published the poem as a freestanding work in 2011 -, serves as a means of considering the relationship between the poet created by Nabokov and the writer himself. This leads, in turn, to Nabokov's peculiar conception of nature, based on the idea of a benevolent

\footnotetext{
${ }^{1}$ Doutor (2017) e Mestre (2011) em Teoria e História Literária pela Universidade Estadual de Campinas. Graduado em Letras (2008) pela Universidade Federal de São Carlos. Campinas, São Paulo, Brasil. E-mail: tauantinti@gmail.com
} 
creator that seems to serve as model for both his characters and his own art.

KEYWORDS: Vladimir Nabokov. Pale Fire.

Metafiction. Late modernism. Natural mimicry. 
Pale Fire, de autoria de Vladimir Nabokov e publicado originalmente em 1962, é um livro no mínimo peculiar, que só com certa reserva pode ser chamado propriamente de um romance. $\mathrm{O}$ volume busca se apresentar como uma edição crítica do último poema de John Francis Shade, chamado "Pale Fire" e composto de 999 versos (ou mil, se o primeiro verso for repetido ao final, como parece ser a intenção) dispostos em uma estrutura simétrica de quatro cantos. A intenção declarada das notas que se seguem ao poema, de cunho marcadamente autobiográfico, é a de fornecer uma realidade concreta que nele não se encontra suficientemente disponível - ainda que seja imprescindível para sua devida apreciação, conforme acredita Charles Kinbote, o responsável pela edição. Shade, é claro, não passa de invenção de Nabokov, e as notas de Kinbote no geral degringolam em comentários e esclarecimentos sobre o próprio crítico, até certo ponto amigo íntimo do poeta e estudioso de sua obra. Para complicar a situação narrativa, vai sendo insinuado aos poucos o verdadeiro propósito da edição comentada: Kinbote parece acreditar que o poema tem como tema não apenas a vida do próprio Shade, mas principalmente tanto a história de Zembla e de seu rei Charles II, deposto por um regime comunista e agora foragido, quanto as desventuras de Jakob Gradus, assassino enviado para eliminar o monarca exilado e que acaba assassinando Shade por engano. E, para tornar as coisas ainda mais insólitas, as notas não tardam a revelar que Kinbote e Charles II são a mesma 
pessoa - ou melhor, para arrematar, que o crítico psicologicamente instável talvez tenha delirado tudo isso e não seja outro que o professor V. Botkin, personagem absolutamente secundário nas notas ao poema, mal chegando a ser nelas mencionado. $^{2}$

A instabilidade mental de Kinbote, bem como sua visão idiossincrática do que seria uma edição crítica acadêmica, ficam claras já desde o prefácio que antecede os versos. Deixando por ora de lado toda a parafernália sobre Zembla e Gradus, notemos também a admiração genuína de Kinbote pelo poeta John Shade, evidente já desde as primeiras páginas do livro:

Here he is, I would say to myself, that is his head, containing a brain of a different brand than that of the synthetic jellies preserved in the skulls around him. He is Looking from the terrace (of Prof. C.'s house on that March evening) at the distant lake. I am looking at him, I am witnessing a unique physiological phenomenon: John Shade perceiving and transforming the world, taking it in and taking it apart, recombining its elements in the very process of storing them up so as to produce at some unspecified date an organic miracle, a fusion of image and music, a line of verse. (NABOKOV, 2000, p. 24.)

A profusão caleidoscópica de autores em potencial e identidades duplas ou triplas gerou quase todo tipo de teoria mirabolante sobre quem seria $o$ "verdadeiro" responsável por esse amontoado sui generis de palavras: Kinbote inventou Shade, Shade inventou Kinbote, o espírito de Hazel Shade, a filha morta de John, animou o espírito do poeta, Kinbote e Shade são almas complementares em estranha sintonia - o céu é o limite. ${ }^{3}$ O livro sem dúvida provoca continuamente esse tipo de engajamento, e os resultados podem ser bastante inventivos e/ou convincentes. Mas nossa intenção será aqui, ao menos a princípio, mais modesta, passando ao largo de todo esse debate. Isto é, a ênfase na admiração de Kinbote por Shade é aqui relevante como forma de abordar um detalhe que já foi assunto de certa consideração pela crítica: Shade descartou versos que Kinbote considera especialmente expressivos - em geral aqueles que, não por coincidência, teriam uma relação um pouco menos tênue com a história de Zembla. Brian Boyd (1991, p. 442) não hesita em considerar tais variantes como obviamente inferiores aos versos do poema acabado, classificando-os como invenção do próprio Kinbote. De outro lado e em sentido bastante diverso, alguém como Richard Rorty (2007, p. 272-273) considera o poema de Shade uma criação no máximo medíocre, algo que é essencial para sua versão de Nabokov:

\footnotetext{
${ }^{2}$ Esta última é, ao menos, a hipótese de Mary McCarthy em "A Bolt From The Blue", um texto influente a ponto de ter sido incorporado como introdução às edições de Pale Fire da Penguin a partir de 2000.

${ }^{3}$ Andrew Field (1967) defende que Shade inventou Kinbote, enquanto Page Stegner (1966) argumenta o contrário; a teoria da sintonia entre Shade e Kinbote é de Brian Boyd (1991), enquanto a centralidade do espírito de Hazel Shade - isso mesmo - consiste em uma reelaboração posterior - e vastamente expandida - do próprio Boyd (1999), em certa medida motivada, como ele próprio admite $(1999$, p. 4), por debates especialmente acalorados em um fórum online dedicado ao escritor.
} 
segundo o filósofo, o escritor russo encena em romances como Pale Fire e Lolita as limitações inerentes ao tratamento estético de questões morais, com artistas cujo solipsismo, se é indiferente ao sofrimento alheio, pode ser também capaz de gerar obras de arte mais relevantes do que as de criadores menos avessos a se deixar afetar por outras individualidades.

Nossa hipótese inicial é então a de que a questão do mérito estético do poema "Pale Fire", metonimicamente presente na avaliação dos trechos descartados por Shade, é muito mais espinhosa do que a mera leitura dos versos sugere, podendo servir de ponte para alcançarmos a concepção de artista (e de arte) subjacente à obra nabokoviana, que é por sua vez ilustrativa da delicada posição em que se encontrava à época, entre os últimos fôlegos da ideia modernista de autonomia. ${ }^{4}$ Comecemos, nesse sentido, pela avaliação de Boyd sobre o caráter forjado das variantes de Kinbote, que pode ser contraposta a um argumento do próprio crítico, feito em um artigo que se opõe frontalmente a certa tendência da crítica de Lolita $^{5}$, que passou algum tempo questionando a veracidade dos últimos acontecimentos relatados por Humbert: se Kinbote produziu ele mesmo os versos descartados, o que o teria impedido de simplesmente fazer interpolações ao poema de Shade? Aliás, de acordo com essa mesma lógica, o que então o teria impedido de inventar completamente não o poeta, mas apenas seu último poema?

Caso Kinbote tivesse de fato agido assim, talvez ele pudesse ao menos ter tornado mais convincente a relação entre poema e comentário, estabelecendo conexões mais sólidas entre os versos falsos de Shade e a história de Zembla que ele gostaria que estivesse sendo cantada. Porém, dada a loucura característica do narrador, um contra-argumento pragmático como este pode não bastar. Digamos então que Kinbote, profundo conhecedor da obra poética de Shade, o teria plagiado, por exemplo. Mas, sendo assim, teríamos também que tomar a admissão do narrador de que é incapaz de produzir versos como uma tentativa de cobrir as pistas de sua falsificação. Ou podemos, de ainda outro lado, propor a impossibilidade da falsificação ter ocorrido como o ponto de sustentação de toda a verossimilhança narrativa de Pale Fire, de modo a ressaltar um elemento importante da estrutura da ficção nabokoviana: sendo o objetivo último de Kinbote imortalizar por meio da arte (mesmo que a de Shade) tanto sua terra natal quanto sua própria história - e nesse sentido pouco importa que ambas sejam não apenas ficcionais, mas que possam ser também mentirosas -, ele precisa da capacidade criadora de Shade, e precisa especialmente acreditar em alguma medida que o poema diz respeito a Zembla e a si mesmo. Não sendo esse o caso, tudo desaba ou não passa de brincadeira.

\footnotetext{
${ }^{4}$ Para uma exploração do modernismo tardio como um momento de elaboração a posteriori da ideia de autonomia da arte, cf. Jameson (2005).

${ }^{5}$ Trata-se da teoria avançada por críticos como Alexander Dolinin (1995) e Julian Connolly (1995), de que os capítulos finais de Lolita teriam sido inventados por Humbert, algo que provocou algum frisson entre os estudiosos de Nabokov.
} 
Ou seja: nessa chave, o livro teria como base interna tanto a grandeza artística do poeta quanto a capacidade do comentador de trazer à luz seus significados ocultos. Porém, isso não implica que John Shade precise ser para nós um grande poeta, mas que funcione como um grande poeta dentro do universo de Pale Fire. E ele de fato funciona, sendo renomado, ganhador de prêmios, colocado no mesmo patamar de Robert Frost e profundamente admirado por Kinbote, que compara sua capacidade artística à mágica, sorvendo aquilo que para sensibilidades inferiores seriam meros detalhes banais do mundo, mas que para o verdadeiro poeta servem de material para um "milagre orgânico", ou o "sudden flourish of magic" que é o poema "Pale Fire" - ainda que este precise dos comentários e esclarecimentos de quem tanto conhece quanto consiste em seu verdadeiro tema oculto. Mas, de novo, com isso não fica necessariamente invalidada uma avaliação depreciativa como a de Rorty, que certamente não está sozinho em seu juízo de valor. O problema é que nossos horizontes de avaliação e os dos personagens do romance são, por definição, fundamentalmente distintos. Não é exatamente que um bom ou mau poema, ou mesmo uma obra prima, sejam coisas diferentes dentro e fora de Pale Fire. Nabokov é com certeza um versificador no mínimo competente, o que pode ser verificado em Poems and Problems ou, de um ponto de vista mais estritamente técnico, nos volumes de notas a sua tradução do Eugene Onegin de Púshkin, em especial seu idiossincrático apêndice sobre versificação em língua inglesa.6 Mas julgar isoladamente o mérito artístico do poema é transformar John Shade em pouco mais do que um heterônimo de Vladimir Nabokov, sem levar em conta o modo como poema e comentário se encaixam, formando simetrias, paralelos ou antecipações curiosamente explicativas e que adensam seu potencial semântico, como é o caso com o dístico "Man's life as commentary to abstruse / Unfinished poem. Note for further use" (NABOKOV, 2000, p. 57), debochadamente autorreferencial no contexto do romance, mas um tanto estéril fora dele. De outro lado, avaliar o poema tendo como critério a riqueza e complexidade do campo de associações estabelecidas com o comentário é justamente não apreciá-lo como poema, mas considerá-lo apenas em sua função, como um meio entre outros, mais ou menos adequado a um fim que lhe é em última instância extrínseco: a arquitetura interna do romance Pale Fire. E, se um tal critério soa inadequado ou insatisfatório para lidar com a realização poética de John Shade, algo que parece a princípio pouco mais do que uma curiosidade editorial ajuda a levar a questão adiante.

\footnotetext{
${ }^{6} \mathrm{Na}$ verdade, mesmo isso é controverso, caso se queira assumir o lado de Edmund Wilson (1965) na polêmica entre ambos, ocorrida na seção de cartas do The New York Review of Books, e que marcou o fim quase definitivo da longa (e sempre belicosa) amizade entre ambos. Para uma defesa da tradução tremendamente idiossincrática feita por Nabokov - que declaradamente tentou torná-la, em suas revisões sucessivas, cada vez mais esvaziada de qualquer sensibilidade poética, tendo seguido nesse esforço ao longo de vários anos -, ver por exemplo o capítulo sobre o Onegin na biografia do escritor escrita por Brian Boyd (1991, p. 318-355).
} 


\section{A EDIÇÃO GINGKO DE PALE FIRE}

Em 2011, a editora Gingko Press, especializada em edições de luxo e volumes com acabamento gráfico refinado, tomou para si a tarefa de libertar o poema de John Shade das garras delirantes de Charles Kinbote. Com efeito, a edição de luxo de "Pale Fire" - aliás, Pale Fire, mas não o Pale Fire de Nabokov (?) - foi recebida e entendida em termos próximos a estes. Em lugar do comentário ficcional de Kinbote, o poema de Shade foi publicado junto de um segundo volume de textos críticos de autores reias, contando com o crítico Brian Boyd e o poeta R. S. Gwynn, que discutem o poema enquanto poema, comparando-o tanto aos melhores sonetos shakespearenos quanto à paisagem poética norteamericana da época (NABOKOV, 2011). Por sinal, o poema alcança sua existência independente e tardia também da forma como Kinbote disse tê-lo encontrado (e surrupiado de Sybil Shade, a esposa de John, conforme se deduz depois): em oitenta fichas de tamanho médio, já passadas a limpo e em sua versão, para todos os efeitos, final - aquilo que o website da Gingko Press vende como a primeira edição fac-similar da obra de Shade, sem qualquer traço perceptível de ironia. $^{7}$ Estes cartões simulam a escrita à mão do poeta, que numerava e marcava as datas em que cada um deles fora preenchido de versos. Vistas mais de perto, contudo, as fichas supostamente amadoras, mas na verdade luxuosas, revelam ter sido produzidas por uma sensibilidade análoga àquela envolvida na fabricação de utensílios de cozinha pseudo-rústicos, cujas imperfeições feitas em série pretendem emular com precisão o desgaste do uso e do tempo sobre os objetos, de modo a despontarem nas prateleiras de uma loja do Pão de açúcar quase como paródias involuntárias dos objetos auráticos de Benjamin $^{8}$ : a primeira ficha com o título, por exemplo, vai ao extremo kitsch de apresentar as manchas produzidas por uma caneca de café deixada distraidamente sobre ela. Não é difícil ver em supostas sutilezas como estas o esforço de criar uma atmosfera íntima, afastando o poema de Shade rumo a uma espécie de tempo pré-kinbotiano, como se os leitores da edição Gingko estivessem eles mesmos se deparando subitamente com um tesouro inesperado e contido em fichas aparentemente banais. A mera comparação entre fichas fictícias como estas e suas contrapartes verdadeiras, como as deixadas pelo próprio Nabokov e que foram publicadas em edições estas sim parcialmente fac-similares sob o título The Original of Laura, com seus rabiscos e letra irregular, às vezes quase ilegível, deixam clara a diferença entre instrumentos de trabalho e uma imitação de artesanato.

\footnotetext{
${ }^{7} \mathrm{O}$ texto que anuncia desse modo o poema está disponível em http://gingkopress.com/shop/palefire/.

${ }^{8}$ Para uma crítica ao conceito benjaminiano de aura que a vincula a seu caráter de antiquário, próximo daquele acima sublinhado, construída a partir de termos do próprio Benjamin, cf. Hullot-Kentor (2009).
} 
Porém, deixando de lado por um instante o que pode parecer não passar de implicância, é importante ressaltar o quanto o poema parece de fato pedir por gestos como esse. Conforme já mencionado, "Pale Fire" é um poema profundamente autobiográfico - isto é, do ponto de vista da diegese -, indo em linhas gerais da infância de Shade, com a experiência supostamente transcendente ocorrida no ataque epiléptico cujo registro encerra o primeiro canto, até considerações metaliterárias situadas próximas ao próprio momento da escrita, e que correspondem inadvertidamente tanto aos últimos dias de vida do poeta quanto aos versos finais do quarto e último canto. Por sua vez, os dois cantos intermediários, ambos com 334 versos, tratam respectivamente da vida de Hazel, filha do casal Shade e algo como um patinho feio paradigmático, até a noite trágica de seu possível suicídio, e da obsessão do poeta com o além-vida, que o levou ao contato com uma provável charlatã, por conta de um erro tipográfico em uma matéria de jornal. Ainda que por vezes bastante a contragosto especialmente com o que diga respeito a Sybil Shade, vista como uma rival na disputa pela atenção do poeta -, Kinbote de fato apresenta diversos acontecimentos da vida de Shade, mesmo que costumem ser ao menos um pouco distorcidos. Contudo, é claro que não é essa a nota dominante de seu comentário, tremendamente mais preocupado com sua própria e fantástica história, com frequência encontrando só as mais esfarrapadas desculpas - o uso de uma expressão banal, a breve menção a uma cor primária - para enxertar no comentário as aventuras do Rei Charles II. Muito do efeito superficialmente cômico do livro decorre dessa disparidade completa entre poema e comentário; numa nota mais séria, mas não menos maluca, o segundo tema que Kinbote se propõe a escavar dos versos é o da aproximação gradual do assassino Jakob Gradus - cuja existência Shade sequer supõe, o que torna a ideia de sua inclusão intencional no poema algo francamente absurdo. Mas, mesmo assim - ou melhor, também por tudo isso -, o comentário de Kinbote funciona como o poderoso centro de gravidade do romance, atraindo para si um poema que não tem como não acabar soterrado, ou com sua possibilidade de voz própria no mínimo abafada. Nesse sentido, a única forma de garanti-la minimamente seria a do distanciamento efetivo entre ambos, por meio de sua publicação independente.

Contudo, é mais adequado dizer que a relação entre poema e comentário se dá sob o signo da ambivalência. Há em "Pale Fire" muito material biográfico tratado com descaso pelo comentador, mas poderia também ser argumentado que sua dispensa sumária inadvertidamente provoca o fortalecimento de um conteúdo humano, já que este insiste em mesmo assim se fazer ouvir, e que diz respeito especialmente ao amor sentido pela companheira, à tristeza decorrente do suicídio da filha e à angústia diante da própria mortalidade. Por outro lado, o núcleo transcendente do poema de Shade é verdadeiramente potenciado pelo comentário, já que trata do estabelecimento de texturas e padrões combinatórios, do contraste 
complexamente ordenado à simetria mais básica, já presente em princípio na forma dos quinhentos heroic couplets de que é composto. Após uma experiência de quase morte na qual visualiza nitidamente uma fonte em toda a sua ipseidade9, e depois da decepção causada pela descoberta de que sua visão não havia sido compartilhada por uma senhora distante, que descrevera não uma fonte [fountain], mas um monte [mountain], fazendo com que tudo não passasse de um erro tipográfico do jornal onde a matéria fora publicada, Shade tem uma epifania ainda mais intensa como fruto desse acidente banal. Eis sua conclusão metafísica:

Life Everlasting - based on a misprint!

I mused as I drove homeward: take the hint, And stop investigating my abyss?

But all at once it dawned on me that this Was the real point, the contrapuntal theme; Just this: not text, but texture; not the dream But a topsy-turvical coincidence,

Not flimsy nonsense, but a web of sense. Yes! It sufficed that I in life could find Some kind of link-and-bobolink, some kind Of correlated pattern in the game, Plexed artistry, and something of the same Pleasure in it as they who played it found. It did not matter who they were. No sound, No furtive light came from their involute Abode, but there they were, aloof and mute, Playing a game of worlds, promoting pawns To ivory unicorns and ebon fauns; Kindling a long life here, extinguishing A short one there; killing a Balkan king; Causing a chunk of ice formed on a high Flying airplane to plummet from the sky And strike a farmer dead; hiding my keys, Glasses or pipe. Coordinating these Events and objects with remote events And vanished objects. Making ornaments Of accidents and possibilities.

(NABOKOV, 2000, p. 53)

Menos importante do que o sonho em si é a coincidência, cujos padrões criam uma teia de sentido, ou ornamentos a partir de acidentes e possibilidades. Ora, segundo essa lógica, o acúmulo de material, ainda que aparentemente disparatado - como, digamos, um comentário ensadecidamente autocentrado, capaz de usar quase qualquer desculpa para falar de outra coisa e fabricando com

\footnotetext{
9 "My vision reeked with truth. It had the tone, / The quiddity and quaintness of its own / Reality. It was" (NABOKOV, 2000, p. 51)
} 
isso relações constantemente problemáticas -, serve no mínimo como palco em potencial para o adensamento das tais redes de sentido. Em um de seus diversos comentários a Pale Fire, Brian Boyd (1991, p. 443 e segs.) argumenta que há no poema de Shade uma abertura abnegada ao comentário desfigurador de Kinbote como forma de produzir sentidos que permaneceriam inacessíveis a uma consciência unificada. Dito de outro modo, a junção textual de duas consciências distintas e também textuais - poeta e crítico - serviria como forma de produzir uma posição que permaneceria inacessível a cada uma delas tomadas isoladamente, no conhecido espírito de um todo que é qualitativamente distinto da soma de suas partes individuais, irremediavelmente presas àquilo que Boyd chama, a partir do próprio Nabokov, de "prison of the self" (BOYD, 1991, p. 228). E, ainda assim, a tensão interna, imanente à cisão entre poema e comentário, produzidos por consciências que são no plano da diegese individualizadas e com propósitos distintos, como que prepara a separação do poema, ou sua suposta superação com relação ao comentário.

Porém, o resultado desse esforço de individuação acaba saindo pela culatra. De um lado, o comentário caótico de Kinbote permitia a um poema regular e autorregrado como o de Shade integrar redes de coerência que permaneceriam de outra maneira inacessíveis. De outro, a particularidade extrema e banal que os cartões pseudo-artesanais buscam simular acrescenta um ruído algo desconfortável à ipseidade da fonte vislumbrada por Shade em sua experiência de quase morte. Para Nabokov como para Shade, as coisas se tornam mais reais justamente por meio da complexidade dos padrões em que estão enredadas, e não de seu isolamento. Ao perder o contato com aquilo que o circundava, "Pale Fire" se torna nesse sentido menos, e não mais real: a aparência de imediatidade se reverte no máximo de distância, pois assim fica ainda mais evidente aquilo que do poema simplesmente não pode ser removido - o fato de que está entre aspas.

A distinção entre John Shade como heterônimo de Vladimir Nabokov e como personagem literário fica especialmente nítida - e significativa - em versos como os do final da estrofe citada há pouco. Ela pode, ao menos por enquanto, ser considerada como pouco mais do que hierárquica, relativa à diferença entre criatura e criador. E o prazer possibilitado pela intuição dessa relação não é apenas por ela mediado, mas torna-se assim também metonímico: "It sufficed that I in life could find / Some kind of link-and-bobolink, some kind / Of correlated pattern in the game, / Plexed artistry, and something of the same / Pleasure in it as they who played it found". Uma instância superior que cria um jogo de padrões intricados - e uma consciência suficientemente atenta e porosa que se satisfaz em percebê-los, em recriá-los em miniatura ou mesmo em imitar seu princípio de criação de padrões. Ou então, Vladimir Nabokov, autor de Pale Fire - e John 
Shade, autor de "Pale Fire". Nas estrofes de conclusão do poema, o mesmo credo torna a aparecer:

\author{
Maybe my sensual love for the consonne \\ D'appui, Echo's fey child, is based upon \\ A feeling of fantastically planned, \\ Richly rhymed life. \\ I feel I understand \\ Existence, or at least a minute part \\ Of my existence, only through my art, \\ In terms of combinational delight; \\ And if my private universe scans right, \\ So does the verse of galaxies divine \\ Which I suspect is an iambic line.
}

(NABOKOV, 2000, p. 57-58)

O prisma por meio do qual Shade compreende a existência - ou, mais humildemente, sua própria existência diminuta - é o de sua arte. A analogia é aqui cristalina: a ordem de seus versos, corretamente rimados e escandidos, é a mesma que a do universo, um alexandrino iâmbico como o seu e o de Alexander Pope, poeta que lhe servira de inspiração e de objeto de estudo na Universidade (fictícia) de New Wye. O núcleo de nosso argumento aqui decorre destes versos: o personagem John Francis Shade, professor universitário e poeta de primeira linha, está rigorosamente correto em sua imagem do universo rimado. É, afinal, essa a textura de seu mundo, que é feito integralmente de versos, mais a prosa de Charles Kinbote onde indiretamente figura. Mas, de novo, trata-se de uma metafísica entre aspas - ou, mais precisamente, de metaficção travestida de metafísica. Tomado isoladamente, libertado do comentário de Kinbote, "Pale Fire" é apenas uma ficção incompleta. E, tomado literal ou imediatamente, "Pale Fire" vira um poema metafísico chinfrim, mera afirmação otimista da textualidade infindável e ilimitada. Para colocar as coisas em termos claros: a reflexão final de Shade faz uso de imagens metalinguísticas com um propósito metafísico evidente; porém, por conta de seu estatuto ficcional, os dois modos de pensamento devém sobrepostos, o segundo correspondendo quase in toto ao primeiro. A referência ao criador que Shade intui diz respeito a uma entidade real em todos os sentidos do termo; ao se tentar suprimir as aspas do poema, a entidade à qual a ideia de criador remetia é necessariamente substituída por outra, cuja existência deixa de ser garantida - ou mesmo verificável. Em suma, a não observância do desnível ou da diferença entre - para sermos generosos - modos de existência distintos acaba por levar à confusão entre metalinguagem e metafísica, algo que compõe o núcleo mais íntimo da poética nabokoviana. Ou então: um criador que ordene a realidade em padrões plásticos existe de fato para Shade, mas não necessariamente para nós - ou ao menos não da mesma maneira. É nesse sentido muito preciso que "Pale Fire" não pode ser julgado e talvez nem mesmo apreciado como poema isolado: ao ser deslocado dessa maneira, seus temas acabam com os sinais trocados. A elaboração formal passa a girar em falso, 
já que o material que a motivara simplesmente se desfaz com a tentativa de remoção das aspas que o continham e que em última instância o constituem.

Apontamos, então, para a sobreposição quase integral de dois modos de pensamento em princípio bastante distintos na reflexão poética de John Shade. Podemos com isso arriscar nesse ponto a seguinte tendência geral da ficção nabokoviana: quanto mais aguda a consciência alcançada pelos personagens de sua própria ficcionalidade, mais próxima será a relação entre metafísica e metaficção em suas reflexões, tendendo a total equivalência entre ambas ao desvelamento, que pode ou não ser temporário, de toda a diegese como um mundo meticulosamente construído por um criador benevolente - uma figura que precisará ser agora tornada mais nítida.

\section{JOHN SHADE, CURIOSAMENTE AGNÓSTICO}

Voltemos novamente a Brian Boyd (1991, p. 426-455), que apresenta uma decifração do suposto mistério da autoria de Pale Fire: Shade teria preparado sua própria morte e composto tanto Kinbote quanto seu assassino Jakob Gradus como forma de realizar o desígnio oculto, e por definição impossível a partir de uma posição unitária, de transcender sua própria perspectiva individual e transmitir uma mensagem que só se poderia tornar coerente e verdadeira pelo recurso paradoxal à dissolução em um conjunto de vozes. Haveria então, de um lado, o sóbrio poeta John Shade e, de outro, as fantasias de seu comentador, capaz como Shade sozinho não o seria - de integrar retroativamente ao poema outras camadas de sentido, das quais a verdadeiramente transcendente e mais importante (além de animada pelo espírito de sua falecida filha Hazel) seria a série de marcas que gravam - ou melhor, criam - o ritmo iâmbico e automático do homem que viria a matá-lo.

Não é necessário que acompanhemos os desdobramentos das elucubrações de Boyd para reconhecer o acerto da conclusão à qual o crítico se vê levado. Pois, segundo argumenta, quanto maior for o domínio de Shade sobre o conjunto formado por poema e comentário, com direito à invenção de Zembla e de seu próprio algoz, mais borrados se tornam seus contornos enquanto personagem, e mais sobreposta fica sua imagem à de Nabokov. Para que isso seja verdade, porém, não é necessário fundirmos Shade, Kinbote e até certo ponto Gradus; poderíamos também considerar que Shade se apresenta como uma das imagens definitivas do verdadeiro artista completo nabokoviano, e que equivale à versão mais realizada possível da autoconsciência ficcional. A singularidade de Shade, a despeito da morte narrativa que o aproxima de outros protagonistas nabokovianos, é que o poeta não recusa sumariamente o modo de existência que intui como sendo o seu; não há nele, concluída a reflexão poética que constitui a parte mais convencional de Pale Fire, qualquer traço do desespero existencial que leva, por exemplo, o Luzhin de The Defense a se defenestrar em direção à morte, ou o Adam Krug de Bend Sinister a confrontar Paduk e os guardas armados de 
sua ditadura. Ao contrário, Shade conclui o poema com a aceitação serena de sua posição subordinada, um criador em miniatura à semelhança daquele que lhe é superior, mas capaz de encontrar um prazer metonímico na correspondência entre a forma de sua arte e a do universo de que é parte. Nesse sentido, seus versos já contém em potencial o ritmo da aproximação de Gradus, e o que a princípio poderia parecer uma imposição de sentido absurda da parte de Kinbote se revela passível de ser neles acolhido sem grandes problemas: se o universo pode ser escandido em iambos, por que não o deslocamento assassino de um autômato?

Shade pode então ser cada vez mais sobreposto a seu criador, sem que isso implique necessariamente no domínio crescente do poeta sobre todo o livro. Seus versos podem funcionar, a partir de sua descoberta metafísica-metaficcional, como um vórtice semântico que passa a ter retroativamente acolhido sentidos que, ainda que extrínsecos, manifestam-se como predeterminados por meio das interpretações selvagens de Kinbote. Seu domínio subterrâneo é menos efeito de uma dissolução subjetiva do que mais apropriadamente de sua grandeza artística vale notar, no universo ficcional de que é parte privilegiada. A escala da autoconsciência ficcional, ao culminar em John Shade, não equivaleria então, como em romances anteriores e menos bem realizados de Nabokov, à dissolução de um mundo fictício que é assim guardado de volta na caixa e recolocado no armário de brinquedos, mas sim na realização máxima de um sistema de padrões que vibra na mesma frequência do mundo que integra. A autoconsciência máxima equivale à constituição subjetiva do artista completo, um criador satisfeito em ser à imagem de um Criador: Shade é sobreposto a Nabokov, mas ambos não são iguais entre si, já que este contém aquele. Se não for esse o caso, a metalinguagem que se mostra dessa perspectiva o cerne de "Pale Fire" passaria a dizer respeito ao tecido de nosso mundo, onde não existe Zembla - nem Charles Kinbote, Jakob Gradus, John Shade ou fantasmas como o de sua filha Hazel. Para recolocar a questão: se de fato no universo nabokoviano a consciência dos personagens de sua própria ficcionalidade equivale à consumação de uma consciência artística capaz de captar a panóplia de detalhes do mundo como densamente organizados em padrões e, a partir destes, contribuir para o seu adensamento por meio da criação de novas redes estruturalmente relacionadas às do mundo, e se essa é em última instância a definição do verdadeiro artista como é sem dúvida o caso de John Shade -, então qual sua relação com o artista responsável por tal escala? Isto é, se o artista efetivamente verdadeiro é o próprio escritor, em que consiste a sua autoconsciência, a partir da qual seria modelada a escala que determina a grandeza de seus personagens?

Questões como estas acabam por nos aproximar de um universo de curiosas ressonâncias teológicas. E, para complicar um pouco mais o problema, um diálogo significativo entre Shade e Kinbote registrado nas notas traz o poeta renegando a existência de deus. A partir de uma conversa algo insossa sobre a existência do pecado, ocorrida em uma das caminhadas dadas pelos dois: 
KINBOTE: Tut-tut. Do you also deny that there are sins?

SHADE: I can name only two: murder, and the deliberate infliction of pain.

(...)

KINBOTE: But who instilled it in us, John? Who is the Judge of life, and the Designer of death?

SHADE: Life is a great surprise. I do not see why death should not be an even greater one.

KINBOTE: Now I have caught you, John: once we deny a Higher Intelligence that plans and administrates our individual hereafters we are bound to accept the unspeakably dreadful notion of Chance reaching into eternity. Consider the situation. Throughout eternity our poor ghosts are exposed to nameless vicissitudes. There is no appeal, no advice, no support, no protection, nothing. Poor Kinbote's ghost, poor Shade's shade, may have blundered, may have taken the wrong turn somewhere - oh, from sheer absent-mindedness, or simply through ignorance of a trivial rule in the preposterous game of nature - if there be any rules.

SHADE: There are rules in chess problems: interdiction of dual solutions, for instance. (NABOKOV, 2000, p. 178-179)

De maneira um tanto surpreendente, é Kinbote quem tenta instilar no amigo a necessidade da crença em uma instância superior. Aliás, mais do que superior, o crítico defende a necessidade de que tal instância seja consciente. Shade renega sem pestanejar um sistema preexistente de crenças calcado na ideia de pecado, reduzindo-o apenas àquilo que considera o núcleo elementar do mal: a crueldade contra os outros, cuja contraparte seria aquilo que Nabokov inclui em uma de suas inúmeras definições da natureza da arte - "beauty plus pity" (NABOKOV, 1982, p. 251). A recusa idiossincrática de uma cosmogonia vagamente cristã, porém, nada tem de leviana. Ao contrário, ela se integra sem grandes dificuldades ao que Durantaye (2007, p. 46 e segs.) define como a rejeição ou indiferença nabokoviana com relação a visões de mundo compartilhadas, o que sem dúvida incluiria um sistema de crença professado por vezes de maneira morna e/ou um tanto irrefletida por parte considerável dos habitantes do mundo. Apesar da implicância de Kinbote, não se pode depurar de seu diálogo com Shade nada parecido com o ateísmo; alguém que considera a possibilidade de um universo ordenado em verso iâmbico e que passou por uma jornada angustiada rumo a tal conclusão não ficaria de modo algum satisfeito com o acaso como lei última. Com efeito, a resposta de Shade à pergunta direta que lhe é feita consiste em uma saída pela tangente: a afirmação de uma ignorâcia tranquila, mas que nem chega a se dar ao trabalho de excluir a possibilidade de um princípio cego a governar a natureza - algo que a simples leitura de seus versos, escritos no mesmo período em que ocorre a conversa entre ambos, bastaria para deixar fora de questão. E, de fato, Kinbote irá em seguida concluir a conversa com um Shade já enfadado: 
KINBOTE: As St. Augustine said, "One can know what God is not; one cannot know what He is." I think I know what He is not: $\mathrm{He}$ is not despair, He is not terror, $\mathrm{He}$ is not the earth in one's rattling throat, not the black hum in one's ears fading to nothing in nothing. I know also that the world could not have occurred fortuitously and that somehow Mind is involved as a main factor in the making of the universe. In trying to find the right name for that Universal Mind, or First Cause, or the Absolute, or Nature, I submit that the Name of God has priority. (NABOKOV, 2000, p. 180)

Da perspectiva de Shade, o erro de Kinbote consistiria apenas na prioridade atribuída ao nome "Deus". De início, nada haveria de errado em uma caracterização negativa como a apresentada; o problema acontece quando o movimento de predicação dos atributos de uma tal entidade superior faz recurso a um arcabouço assumido irrefletidamente como evidente em si mesmo, pelo simples fato de ser compartilhado e disponível a quase qualquer um. Nesse sentido, uma concepção preexistente de um princípio ordenador divino se encontra perigosamente próxima de um charlatanismo como o da mulher no poema de Shade, que de início minara a quidditas da fonte visualizada em delírio de quase morte com sua descrição de um monte genericamente transcendente, levando o poeta a quase pôr abaixo seu sistema de crença individual antes de ser finalmente alçado à plenitude da percepção ainda mais enfaticamente singular da "web of sense" capaz de envolver potencialmente a tudo.

A conclusão um tanto simplória de que Shade está mais perto de um agnosticismo do que do ateísmo pode soar um pouco frustrante, mas apenas se não levarmos em conta que a divindade por ele intuída não apenas existe, como consiste no escritor Vladimir Nabokov. Mas, mais do que isso, a recusa compartilhada por Kinbote e Shade de um universo regido pela lei cega do acaso deixa entrever um ponto de contato entre a autoconsciência do poeta - com sua contraparte sem dúvida mais rudimentar no crítico - e a recusa também sumária de seu criador a conceber o nosso universo da mesma maneira.

\section{SOBRE CERTO CRIADOR BONDOSO}

"Every great artist is a great deceiver", Nabokov costumava dizer na palestra introdutória a seu curso de literatura ocidental em Cornell,

but so is that arch-cheat Nature. Nature always deceives. From the simple deception of propagation to the prodigiously sophisticated illusion of protective colors in butterflies or birds, there is in Nature a marvelous system of spells and wiles. The writer of fiction only follows Nature's lead. (NABOKOV, 1982, p. 5) 
Afirmações como estas são recorrentes em toda a obra do escritor, seja em suas cartas, romances, entrevistas, prefácios ou palestras. Do aforismo declaradamente antidarwiniano de Charles Kinbote - "The one who kills is always his victim's inferior" (NABOKOV, 2000, p. 185) - à exuberância descritiva do capítulo de sua autobiografia em que trata da paixão pela lepidopterologia, Nabokov segue sempre disposto a insistir em uma concepção idiossincrática da natureza - bem como de sua relação com a arte. Conforme Boyd (1991, p. 37 e segs.) deixa claro, trata-se de uma questão das mais importantes para o escritor: logo que começou a lecionar no Wellesley College, ainda no início de sua carreira intelectual nos Estados Unidos, anunciou em cartas a intenção de produzir um artigo que consistiria em uma "refutação furiosa da 'seleção natural' e da 'luta pela vida'". Se é que o texto foi de fato escrito, não chegou a ser publicado, ainda que parte de suas ideias tenham sido incorporadas a Speak, Memory, passando por uma reelaboração literária que nos interessa muito mais de perto. Trata-se do final de um parágrafo que é central para a obra nabokoviana:

When a butterfly has to look like a leaf, not only are all the details of a leaf beautifully rendered but markings mimicking grub-bored holes are generously thrown in. "Natural selection," in the Darwinian sense, could not explain the miraculous coincidence of imitative aspect and imitative behavior, nor could one appeal to the theory of "the struggle for life" when a protective device was carried to a point of mimetic subtlety, exuberance, and luxury far in excess of a predator's power of appreciation. I discovered in nature the nonutilitarian delights that I sought in art. Both were a form of magic, both were a game of intricate enchantment and deception. (NABOKOV, 1989, p. 98)

Em uma entrevista concedida em 1969, Vladimir Nabokov deixa as coisas ainda mais claras: questionado já de início sobre o propósito da série de artifícios e truques de prestidigitação verbal contidos em suas criações, ele rebate a necessidade de qualquer tipo de justificativa - em seus termos, de uma utilidade com o comentário de que ardis [deceptions] ainda mais requintados são produzidos por "that other V.N., Visible Nature" (NABOKOV, 1990, p. 153). Não se trata, para o escritor, da utilidade de seus truques, mas sim de uma lógica do ardil que consiste justamente naquilo que ultrapassa a utilidade. O núcleo de seu argumento contra a ideia darwiniana de seleção natural se encontra no parágrafo em questão: ela é insuficiente para "explicar a coincidência milagrosa de aspecto imitativo e comportamento imitativo" do mimetismo natural, que é tanto recorrente na natureza quanto supostamente excede em larga medida as capacidades perceptivas dos predadores. Sendo de fato esse o caso, a evolução passa a poder ser concebida como não sendo determinada pela adaptação progressiva às condições do ambiente: se o processo que plasma ao ambiente os insetos de que fala Nabokov pode não servir à finalidade de protegê-los de seus inimigos naturais, surge a possibilidade de conceber a partir da natureza uma 
lógica desprovida de qualquer tipo de utilidade prática. Nesse sentido, ela deixaria de ser o reino da autopreservação como princípio último para passar a poder servir de modelo para uma arte também desprovida de utilidade. A coincidência milagrosa de detalhes díspares envolvidos na emulação desnecessariamente perfeita da mariposa que finge se tornar vespa aponta para uma presença dadivosa que não se deixa coibir por critérios como o da eficiência; ao contrário, a sutileza extrema envolvida no milagre mimético estaria a serviço de sua própria beleza, em última instância concebida, como argumenta Boyd (1991, p. 37), para ser percebida por olhos humanos suficientemente atentos para a riqueza de padrões assim engendrados. Trata-se de uma inversão rigorosa do princípio de utilidade darwiniano: o fato de a camuflagem servir também de proteção contra predadores em potencial não passa, na concepção nabokoviana, de subproduto de um processo que permanece em última instância insondável, compondo uma lógica que pode ter apenas o seu vulto vislumbrado, mas nunca perfeitamente compreendido. Ou, como defende Gerard De Vries (1995, p. 142), a rejeição que Nabokov faz do utilitarismo é tão intensa que a inutilidade se torna para ele algo como um fim em si mesmo.

Assim como De Vries, outros críticos se debruçaram sobre a recusa nabokoviana do paradigma darwiniano. David Andrews (2000/2001, p. 3 e segs.), por exemplo, enfatiza que o determinismo não é substituído pelo escritor pela aleatoriedade ou pela indeterminação, mas sim por uma visão essencialmente otimista da natureza e do espírito humano, que não se deixa reduzir à luta pela sobrevivência e permanece sempre capaz de se entregar ao prazer imediato de viver. Com efeito, segundo Andrews (2000/2001, p. 17), ainda outra camada da posição de Nabokov diria respeito a seu repúdio de perspectivas generalizantes capazes de esvaziar qualquer possibilidade de mistério de uma realidade inesgotável, que deveria consistir no que chama de uma sucessão infinita de passos aproximativos. Conforme ainda Durantaye (2007, p. 155) argumenta, a diatribe antidarwiniana do escritor é no mínimo dupla: de um lado, rechaça uma teoria que vê no caso particular apenas o exemplo de uma lei geral inflexível e planificadora - e o mesmo se aplicaria ao marxismo e à psicanálise, aliás; de outro, o próprio conteúdo dessa lei seria problemático, já que resulta em um universo mecânico onde não existe espaço para a gratuidade, o que reduz a exuberância de detalhes naturais, tão caros ao escritor, a meras estratégias de sobrevivência, passíveis de serem quantitativamente medidas pela régua da eficiência.

Nabokov concebe, a partir do mimetismo natural, uma natureza que não segue cegamente o princípio da autopreservação, e modela a partir de suas "delícias não-utilitárias" a sua própria arte, igualmente baseada em ardis que se deixam entrever apenas pelo olhar atento e detido, assinalando uma presença ordenadora que se insinua como insubmissa à pura utilidade. Mas a base de seu argumento é das mais frágeis, e consiste no limite em pouco mais do que uma projeção de sua própria técnica artística na natureza: conforme notado por Durantaye (2007, p. 152), a tal coincidência de aspecto e comportamento de que fala Nabokov não necessariamente ultrapassa a percepção dos predadores, tal 
como ele nos informa com certo desdém. Com efeito, não seria exagero dizer que o escritor simplesmente subestima os predadores de seus insetos milagrosos, desconhecendo o alcance real de suas capacidades perceptivas: o fato de que a beleza ardilosa da natureza seja em casos como esses espantosamente requintada de modo algum basta para dizer que seus truques não dizem respeito também e em última instância à luta pela sobrevivência. Sendo esse o caso, a lógica de Nabokov percorre um círculo ao invés de traçar sua saída: sua arte, definida pela complexidade dos padrões que engendra, além de repleta de sinais que apontam com graus de variados de sutileza para sua presença efetiva como criador oculto, no geral mais visível para seus leitores do que para seus personagens - à exceção, notável e complexa, de John Shade -, se crê modelada a partir de um criador oculto que apresenta o mesmo modus operandi com relação à natureza, intuído a partir da observação de fenômenos como o mimetismo natural, que revelam uma vida cuja riqueza ultrapassaria em muito a mera sobrevivência. Contudo, o que se dá é exatamente o contrário: Nabokov não é um artista concebido à imagem de um deus escondido, mas é esse mesmo deus que foi por ele concebido à sua imagem de artista. É essa a chave para a sobreposição da metaficção à metafísica que reside no cerne de sua ficção: seus personagens chegam mais ou menos perto de captá-la, convertendo-se em imagens mais ou menos parciais do artista completo que seria o próprio Nabokov, responsável por reproduzir em suas obras a dinâmica que julgou encontrar na natureza. Sua presença é indiscutivelmente bondosa por consistir naquilo que permite superar a vida como autopreservação, mas sem com isso abdicar de toda possibilidade de lógica e recair no caos sensório ou na multiplicidade desordenada de fenômenos: conforme argumenta Durantaye (2007, p. 166 e segs.), a luta pela sobrevivência não é suplantada na ficção do escritor por um mundo que carece de qualquer ordem imanente, mas, ao contrário, a atenção suficientemente treinada é capaz de perceber a presença de padrões ricamente compostos, sendo sua beleza plástica a forma de manifestação de um princípio ordenador que assegura a possibilidade de sentido para a existência e com isso freia a angústia decorrente de uma plenitude perceptória que seria de outro modo esmagadora.

Contudo - e podemos nesse ponto apenas sugerir a hipótese, à guisa de conclusão -, a base de uma arte como a de Nabokov consiste em uma concepção da natureza como reconciliada já de antemão, e que é sempre capaz de ensinar àquele que dela se distancia o caminho mental que a ela leva de volta. Caso não seja de fato assim, isto é, caso haja na natureza não somente beleza, mas também e especialmente um sofrimento até agora indizível, com o qual não aprendemos ainda a lidar de forma minimamente adequada ${ }^{10}$ - possibilidade que dificilmente é descartável -, o curto-circuito entre metafísica e metaficção que anima as criações de Nabokov, por mais faíscas de inegável beleza que possa produzir,

\footnotetext{
${ }^{10}$ Vale notar, caso não tenha ficado claro, que o tratamento da questão feito por Adorno e Horkheimer (2006) em A dialética do esclarecimento, em especial o capítulo sobre o conceito de esclarecimento, anima em grande medida as ressalvas aqui feitas à concepção de natureza subjacente à ideia nabokoviana do Criador como artista.
} 
parece permanecer em última instância impotente diante de predadores mais sutis, talvez não exatamente naturais, mas que podem assim seguir subestimados - ou sequer percebidos.

\section{REFERÊNCIAS}

ADORNO, Theodor; HORKHEIMER, Max. Dialética do Esclarecimento. Traduzido por Guido de Almeida. Rio de Janeiro: Zahar, 2006.

ANDREWS, David. Varieties of Determinism: Nabokov among Rorty, Freud, and Sartre. Nabokov Studies, v. 6, 2000/2001.

BOYD, Brian. Vladimir Nabokov - The American Years. Princeton, New Jersey: Princeton UP, 1991.

. 'Even Homais Nods': Nabokov's Fallibility, or, How to Revise Lolita. Nabokov Studies, v. 2, 1995.

Nabokov's Pale Fire: The Magic of Artistic Discovery. Princeton, New Jersey: Princeton University Press, 1999.

DE VRIES, Gerard. 'Perplex'd in the Extreme': Moral Facets of Vladimir Nabokov's Work. Nabokov Studies, v. 2, 1995.

DOLININ, Alexander. Nabokov's Time Doubling: From the Gift to Lolita. Nabokov Studies, v. 2, 1995.

DURANTAYE, Leland de la. Style is Matter - The Moral Art of Vladimir Nabokov. Ithaca, NY: Cornell UP, 2007.

FIELD, Andrew. Nabokov: His Life in Art. New York e Toronto: Little, Brown and Co., 1967.

HULLOT-KENTOR, Robert. "O que é reprodução mecânica?". Traduzido por Tauan F. Tinti). Remate de Males, v. 29, n. 1, 2009.

JAMESON, Fredric. Modernidade singular - Ensaio sobre a ontologia do presente. Traduzido por Roberto Franco Valente. Rio de Janeiro: Civilização Brasileira, 2005.

NABOKOV, Vladimir. Lectures on Literature. San Diego, New York: Harcourt, 1982.

1989.

Speak, Memory - An Autobiography Revisited. New York: Penguin, 
. Strong Opinions. Nova York: Random House, 1990b.

. Pale Fire. London: Penguin, 2000.

. Pale Fire: A Poem in Four Cantos by John Shade. Berkeley, CA:

Gingko Press, 2011.

NABOKOV, Vladimir; WILSON, Edmund. Letters: The Strange Case of Nabokov and Wilson. The New York Review of Books, 26 ago. 1965. Disponível em < $<$ ttp://www.nybooks.com/articles/1965/08/26/letters-the-strangecase-of-nabokov-and-wilson/>.

RORTY, Richard. O barbeiro de Kasbeam: Nabokov sobre a crueldade. IN: RORTY, Richard. Contingência, ironia e solidariedade. São Paulo: Martins Fontes, 2007.

STEGNER, Page. Escape into Aesthetics: The Art of Vladimir Nabokov. New York: The Dial Press, 1966.

Página com a descrição do produto Pale Fire no website da Gingko Press: $<$ http://gingkopress.com/shop/pale-fire/>.

Recebido em 14/09/2017

Aceito em 19/12/2017 